\title{
Gastric and duodenal polyps in familial adenomatous polyposis: a prospective study of the nature and prevalence of upper gastrointestinal polyps
}

\author{
R G SARRE, A G FROST, D G JAGELMAN, R E PETRAS, M V SIVAK, \\ AND E MCGANNON
}

From the Department of Colorectal Surgery, Department of Pathology, and Department of Gastrointestinal Endoscopy, The Cleveland Clinic Foundation, Cleveland, Ohio, USA

SUMMARY One hundred patients with familial adenomatous polyposis have prospectively undergone gastroduodenoscopy to identify and characterise polyps found. Forty six patients had polyps in the stomach or duodenum. Thirty five patients had adenomas ( 33 in duodenum, two in stomach) and 26 patients had fundic gland polyps. Some of these patients had polyps in the stomach and the duodenum. Adenomas in the duodenum were present in $33 \%$ of patients studied with Gardner's syndrome variant $(p=0 \cdot 04)$. Adenomas were also more common in older patients. As adenomas may be a precursor of adenocarcinoma, routine surveillance of the stomach and duodenum with gastroduodenoscopy is recommended in patients affected with familial adenomatous polyposis.

Familial polyposis coli was recognised as an entity as early as $1890 .^{\prime}$ Gardner $^{2}$ described a family with extracolonic manifestations of the disorder which now bears his name. Since that time a number of extracolonic lesions, both benign and malignant, have been reported in association with familial polyposis coli. ${ }^{3}$ Various authors ${ }^{+11}$ have described gastric and duodenal polyps in such families and these are thought to be quite common. Because of the reported high frequency of polyps outside the colon in these patients we prefer to use the name familial adenomatous polyposis rather than familial polyposis coli.

This paper documents the prevalence and nature of gastric and duodenal polyps in 100 patients prospectively undergoing upper gastrointestinal endoscopy.

\section{Methods}

PATIENTS

The Familial Polyposis Registry at the Cleveland

Address for correspondence: David (; Jagelman. MI), Department of Colorectal Surgery. Cleveland Clinic Foundation. 9500 Fuclid Avenue. Cleveland, Ohio 44l16, USA.

Received for publication 20 Junc 1986.
Clinic Foundation established in 1979 now follows 138 families including a total of 501 individuals known to have familial adenomatous polyposis. One hundred and eighty nine individuals in this group are actively managed at the Cleveland Clinic.

In 1980 a prospective study was started to carry out gastroduodenoscopy on patients affected with familial adenomatous polyposis. The patients were examined with the Olympus GIF-XQ10 end view and JF-1T side view fibreoptic gastroduodenoscope. A search was made for macroscopic lesions in the stomach and duodenum. Affected areas were biopsied with particular attention being given to the region of the papilla of Vater. Dye spraying techniques were not used. Random biopsies of the papilla of Vater have been taken recently but this was not routinely done in this study, macroscopic lesions of the papilla alone being biopsied in some cases. To date 100 patients have been examined. Only patients with definite familial adenomatous polyposis or Gardner's syndrome variant have been included. Familial adenomatous polyposis has been diagnosed when a person is found to have more than 100 colorectal adenomas and in whom a family history of such polyps is obtained. Some younger patients have been diagnosed as a result of the Familial Polyposis 
Registry screening programme before developing numerous polyps but these patients have had multiple adenomas along with a typical family history. A few other patients exhibiting typical features of the syndrome but without a family history have been included in the study. These most likely represent spontaneous mutations. The presence of various extracolonic lesions including osteomas of the skull and jaw, epidermoid cysts, subcutaneous fibromas and desmoid tumours were recorded in each case. In a few patients barium meal examination was carried out, however, contrast studies were found to be insufficient in detecting small polyps and the procedure was abandoned. Gastroduodenoscopy together with biopsy where appropriate was utilised in all cases to document the presence of polyps in this study. Biopsies were taken from all patients with macroscopic polyps though not of course from all polyps. Accurate counts of polyps proved difficult and estimates of numbers were used. The biopsy specimens were assessed by a single pathologist (REP) to insure uniformity of reporting. The prevalence of polyps detected in families in which only one member was studied was compared with the prevalence in families in which more than one member was studied. This was done to see if certain families are predisposed to develop upper gastrointestinal polyps in this syndrome.

\section{Results}

One hundred patients with familial adenomatous polyposis prospectively underwent upper gastrointestinal endoscopy. Forty eight were men and 52 women. The mean age at examination was 34 years (range 13-73). Fifty four patients were free of polyps while 46 patients were found to have polyps. Seventeen patients had incidental findings on

Table 1 Prevalence of upper gastrointestinal polyps*

\begin{tabular}{lr}
\hline Normal endoscopy & 54 patients \\
Fundic gland polyps (stomach) & 26 patients \\
Adenomatous polyps (duodenum) & 33 patients \\
Adenomatous polyps (stomach) & 2 patients \\
\hline
\end{tabular}

*Some patients had more than one variety of polyp.

Table 2 Prevalence of polyps by age group

Age
\begin{tabular}{llrl}
\hline 20 & $21-30$ & $31-40$ & 40 \\
$(n=14)$ & $(n=33)$ & $(n=25)$ & $(n=28)$ \\
\hline 4 & 7 & 9 & 6 \\
2 & 6 & 11 & 14 \\
0 & 0 & 1 & 1 \\
\hline
\end{tabular}

Table 3 Prevalence of polyps in Gardner's syndrome and familial adenomatous polyposis

\begin{tabular}{lll}
\hline & $\begin{array}{l}\text { Gardner's } \\
\text { syndrome }\end{array}$ & $\begin{array}{l}\text { Familial adenomatous } \\
\text { polyposis }\end{array}$ \\
\hline Normal examination & $19 / 54(35 \%)$ & $35 / 54(65 \%)$ \\
Fundic gland polyps & $10 / 26(38 \%)$ & $16 / 26(62 \%)$ \\
$\begin{array}{c}\text { Adenomatous polyps } \\
\text { (duodenum) }\end{array}$ & $19 / 33(58 \%)$ & $14 / 33(42 \%)$ \\
$\begin{array}{c}\text { Adenomatous polyps } \\
\text { (stomach) }\end{array}$ & $1 / 2(50 \%)$ & - \\
\hline
\end{tabular}

endoscopy including colon hiatus hernia (12), oesophagitis (four), gastritis (four) and duodenal ulcer (two).

Table 1 shows the prevalence of different types of polyps in the stomach and duodenum detected by gastroduodenoscopy and biopsy. Thirty three patients had duodenal polyps and 28 patients had gastric polyps with 20 patients having polyps in more than one site. Duodenal polyps were exclusively adenomas (tubular pattern 26, villous pattern seven). Gastric polyps were almost always fundic gland polyps (26 of 28 cases). In two patients gastric adenomas were found.

SEX

Fifty two women were examined. Sixteen had duodenal adenomas (14 tubular pattern and two villous pattern) and 11 exhibited gastric fundic gland polyps. One woman had a tubular adenoma in the stomach. Forty eight men were studied. Seventeen had duodenal adenomas (12 tubular pattern and five villous pattern) and 15 exhibited fundic gland polyps in the stomach. One male patient was found to have a gastric adenoma. Thus there appears to be no significant difference between the sexes in prevalence of any category of polyp in patients with familial adenomatous polyposis.

AGE

The prevalence of the various polyps as a function of patient age is presented in Table 2. There were 14 patients in the study age 20 years or less, 33 patients age 21 to 30 years, 25 patients age 31 to 40 years, and 28 patients over the age of 40 years. The prevalence of duodenal adenomas appeared to increase with age. Of the 47 patients below the age of 30 years, eight were found to have adenomas $(17 \%)$. Of the 53 patients over age 30 years, 25 were found to have adenomas $(47 \%)$. On the other hand the frequency of fundic gland polyps do not seem to vary with age. Eleven of 47 patients below the age of 30 years were found to have fundic gland polyps $(23 \%)$, which 15 of 53 patients over the age of 30 years $(28 \%)$ demonstrated such polyps. 


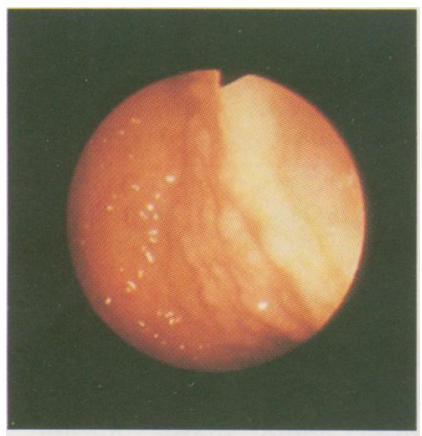

Fig 1

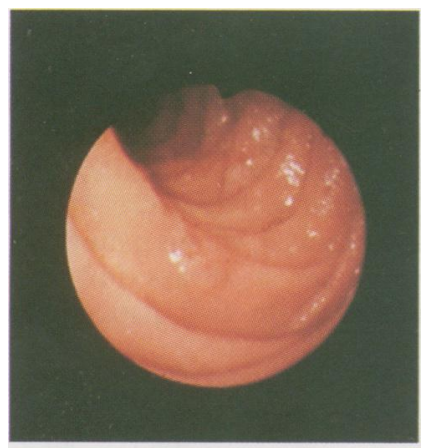

Fig 4

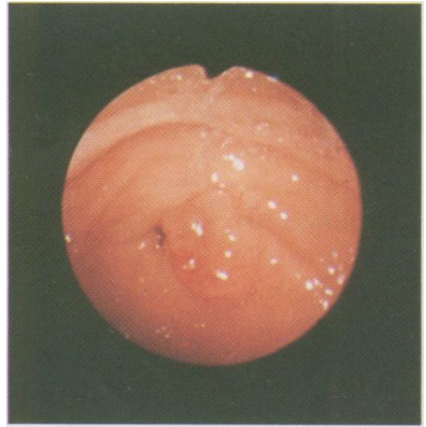

Fig 2

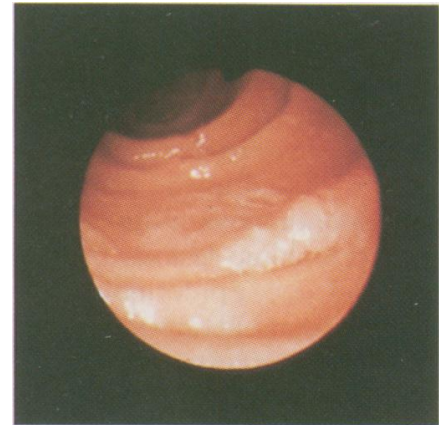

Fig 3

Fig. 1 Retroverted endoscopic view of gastric fundus showing multiple 2-5 mm hemispheric polyps seen directly and in profile to centre right of photograph.

Fig. 2 Irregular shaped, lobulated tubular adenoma of about I cm in diameter seen to the right of nearly closed pyloric ring.

Fig. 3 Flat, sessile tubular adenoma, $8 \mathrm{~mm}$ in diameter, in patient with Gardner's variant.

Fig. 4 Flat, sessile tubular adenoma on apex of valvular fold in a patient with Gardner's variant.

FAMIIIAL INCIDENCE

There were 40 patients where no other family member was studied. Twelve of these had gastric polyps $(30 \%)$ and 18 had duodenal polyps $(45 \%)$. Using these as an expected prevalence, the distribution was calculated for families where two or more individuals were studied. For both gastric and duodenal polyps the prevalence was similar to that expected from the group where a single member only was studied. This suggests that the existence of a relative with upper gastrointestinal polyps is not in itself a risk factor for developing such polyps.

\section{GARDNER`S SYNDROME}

In this study population 37 of the 100 patients $(37 \%)$ had the features of the Gardner's syndrome variant. Table 3 shows the prevalence of Gardner's stigmata related to the presence of gastric and duodenal polyps. Patients with duodenal polyps were more likely to have Gardner's syndrome $(p=0 \cdot(04)$ but this did not apply for gastric polyps. Indeed the reverse seemed to be true. It should be noted, however, that the absence of Gardner's syndrome stigmata did not in any way preclude the development of gastric or duodenal polyps.
ENDOSCOPIC FEATURES OF GASTRIC POLYPS

Most polyps seen in the stomach were of the fundic gland variety. Endoscopically these appeared as small $(1-5 \mathrm{~mm})$ hemispherical polyps scattered through the fundus and extending into the body of the stomach. They were less common both in the cardia and the distal stomach, though occasionally present. They tended to occur in bunches or clusters, grouped fairly close together. These polyps were often of the same colour as normal gastric mucosa although at times they seemed to have paler or lighter orange colour. The number of polyps varied from a few to several hundred in different patients. They were best seen with the gastroscope retroverted for a view of the fundus.

Adenomas were seen in the stomachs of two patients. In neither case was there underlying gastritis or metaplasia. In one case a single adenoma was present in the proximal stomach, discovered among a number of small fundic gland polyps while in the other case three adenomas were situated in the distal stomach. Both patients had tubular adenomas in the duodenum as well. One of these patients also developed an extensive villous adenoma on his ileostomy requiring excision. Endoscopically 


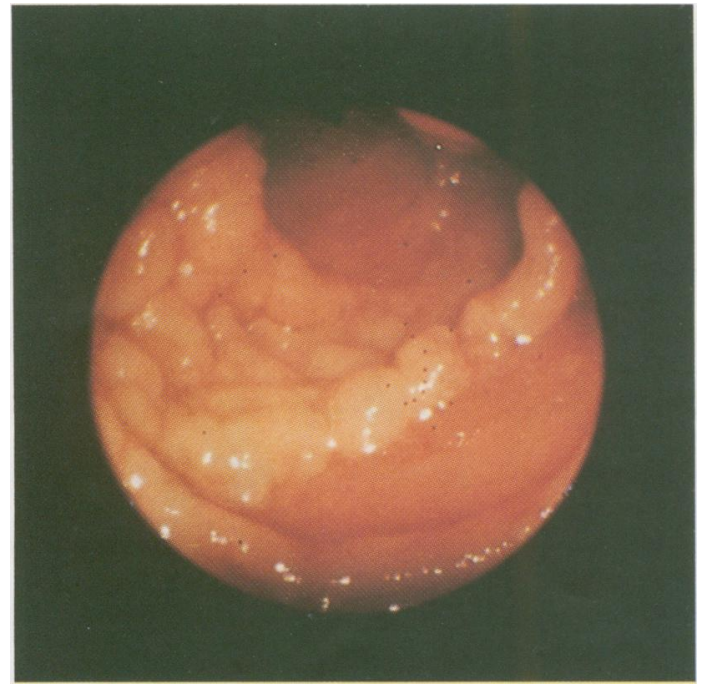

Fig. 5 Cluster of tubular adenomas in patient with Gardner's variant. Note pale colouring compared with surrounding mucosa.

adenomas were larger, rounder and more lobulated or pedunculated when compared to the fundic gland polyps.

\section{ENDOSCOPIC FEATURES OF DUODENAL POLYPS} Duodenal adenomas were observed in 33 patients. The second part of the duodenum was always involved but the first part rarely so. The number of polyps varied from a single lesion to profuse carpeting of the mucosa.

The endoscopic appearance of many duodenal polyps was quite subtle. The duodenal adenomas had an irregular shape and even if large tended to be only slightly raised $(1-2 \mathrm{~mm})$ rather than clearly pedunculated. Larger adenomas occasionally showed an overhanging edge. Most duodenal polyps were small, being $3-5 \mathrm{~mm}$ in diameter. On close inspection the surface texture almost always appeared irregular or even granular. It was not uncommon to find adenomas at the apex of valvular folds. A consistent feature was a pale or white colour of the adenoma in contrast with the normal tan hue of the duodenal mucosa.

The region of the papilla of Vater is often affected by adenomatous change with only minor endoscopic alteration. We found villous adenoma on biopsy from two patients with apparently normal papilla. Both also had other duodenal adenomas (Fig. 6).

\section{HISTOPATHOLOGIC FEATURES}

Fundic gland polyps

Sections of fundic gland polyps showed an apparent overgrowth of fundic glands associated with distor- tion of the gastric mucosal architecture (Figs. 6 and 7). This was associated with abnormal cyst formation involving gastric glands and occasionally foveolar epithelium. The cystic dilatation of the gastric glands proved to be the single best criterion in recognising the lesion in small biopsy specimens. Gastritis, intestinal metaplasia, and dysplasia were consistently absent in biopsies of these polyps.

\section{Gastric adenomas}

Gastric adenomas appeared similar to tubular adenomas of the colon and gastric adenomas seen in non-polyposis patients. Gastric adenomas showed a proliferation of mildly dysplastic cells exhibiting decreased intracellular mucin, increased nuclear size with hyperchromasia, increased numbers of mitotic figures and slight nuclear stratification. The dysplastic cells of the adenoma invariably involved the foveolar region with sparing of the gastric gland (Fig. 8). Adenomas were not associated with atrophy of either antral or fundic glands. Slight chronic inflammation of the antral glands was present in one case. Alcian blue - PAS stain demonstrated acid mucins focally within the cells of the adenoma. Focal intestinal metaplasia could be found in one or two gastric pits immediately adjacent to the adenomas.

\section{Duodenal adenomas}

Duodenal adenomas were similar in appearance to their gastric counterparts. Twenty six patients had tubular adenomas (Fig. 9) while seven were predominantly villous in character. In five patients Brunner's glands were present within the biopsy specimen. In all five the Brunner's glands appeared prominent and were associated with mild cystic dilatation (Fig. 10).

\section{Discussion}

The nature of upper gastrointestinal polyps in familial adenomatous polyposis is becoming more clear, both clinically and pathologically. There appears to be two separate patterns of polyposis which may coexist. In the stomach there may be a variable number of small hemispherical polyps seen. These may be profuse and are usually concentrated in the fundus of the stomach. Histologically they have been termed funic gland polyps.' True adenomas in the stomach seem to be rare with most cases having been reported in Japanese patients. ${ }^{512}$ Duodenal polyps tend to be concentrated around the papilla of Vater and the second portion of the duodenum and again are frequently multiple. Histologically they are adenomas and are generally considered as premalignant. The reported prevalence of gastroduodenal polyps in familial adenomatous polyposis varied from $40 \%-100 \%$. ${ }^{41012}$ The higher rates have been 


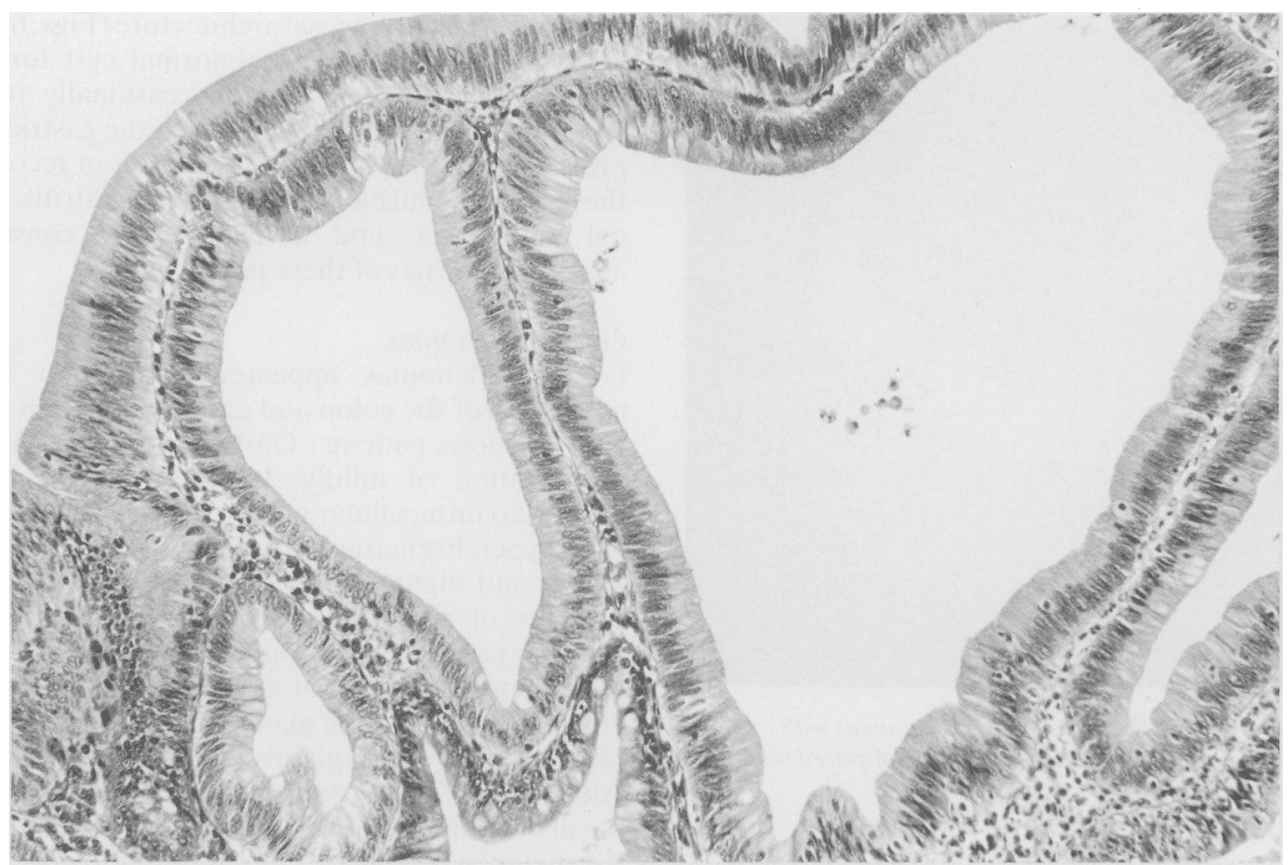

Fig. 6 Adenomatous epithelium encountered on biopsy of an endoscopically unremarkable papilla of Vater. Note the mild nuclear enlargement, crowding and stratification. $(H+E)$.

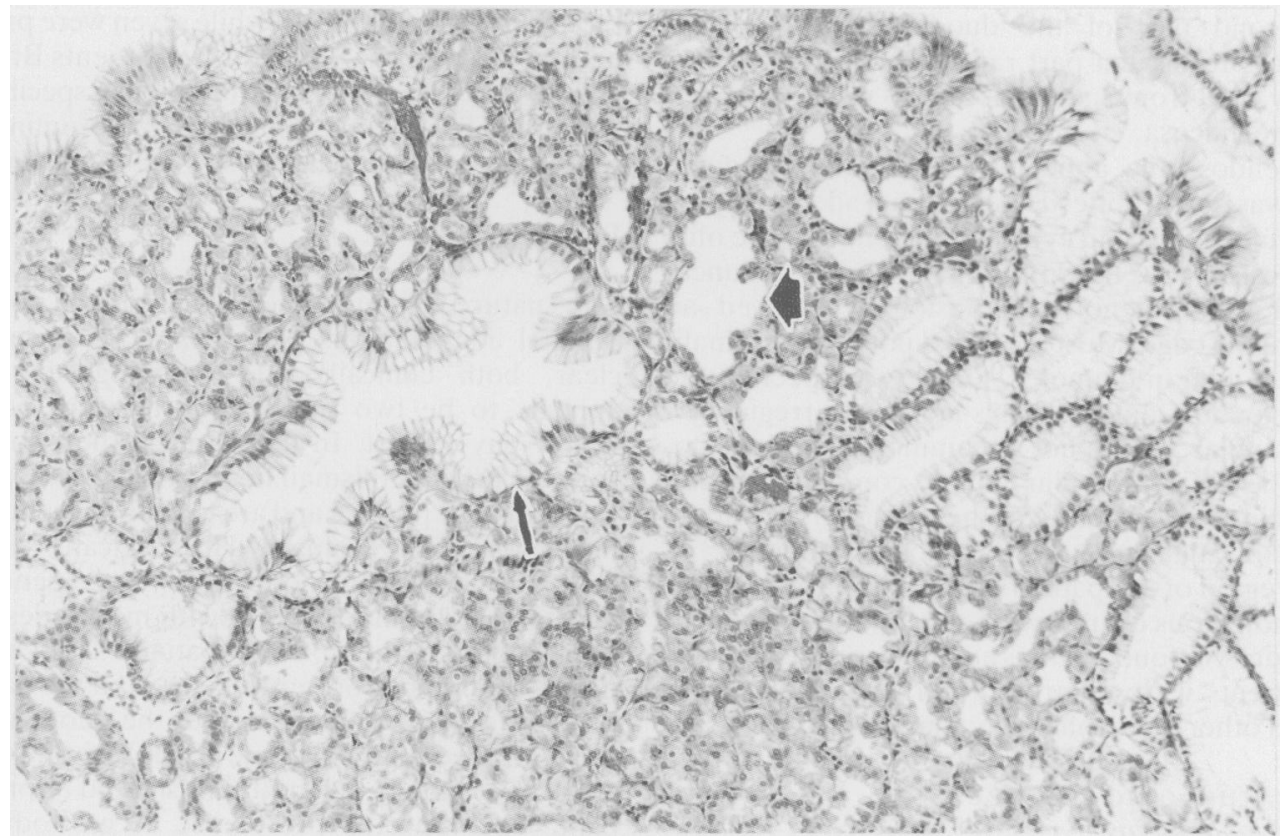

Fig. 7 Typical fundic gland polyp. There is an apparent overgrowth of gastric glands associated with abnormal cyst formation involving glands (large arrow) and foveolar epithelium (small arrow). $(H+E)$. 


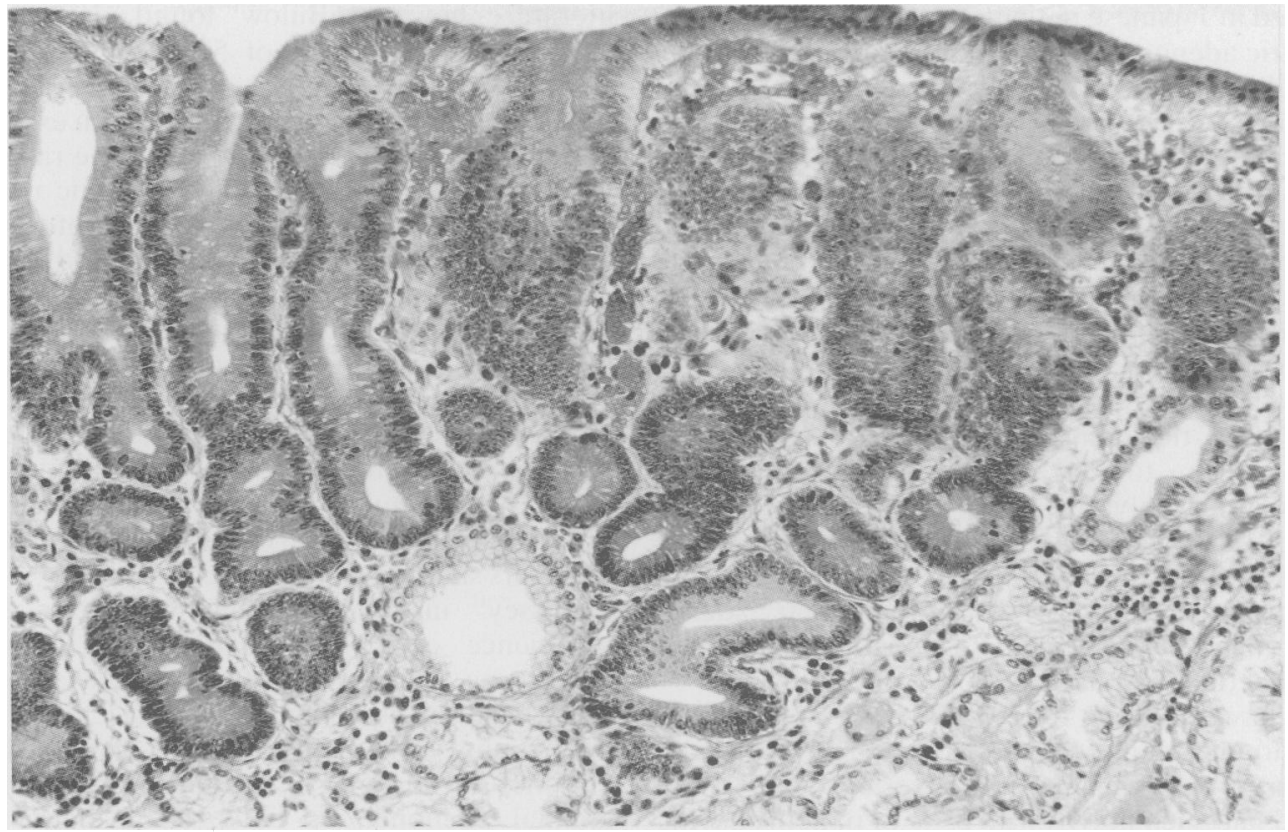

Fig. 8 Tubular adenoma of gastric antrum. The adenomatous epithelium (top) exhibits mild dysplasia with decreased intracellular mucin, increased nuclear size with hyperchromasia, and slight nuclear crowding with stratification. The adenomatous epithelium involves the foveolar region with sparing of the antral glands (bottom). $(H+E)$.

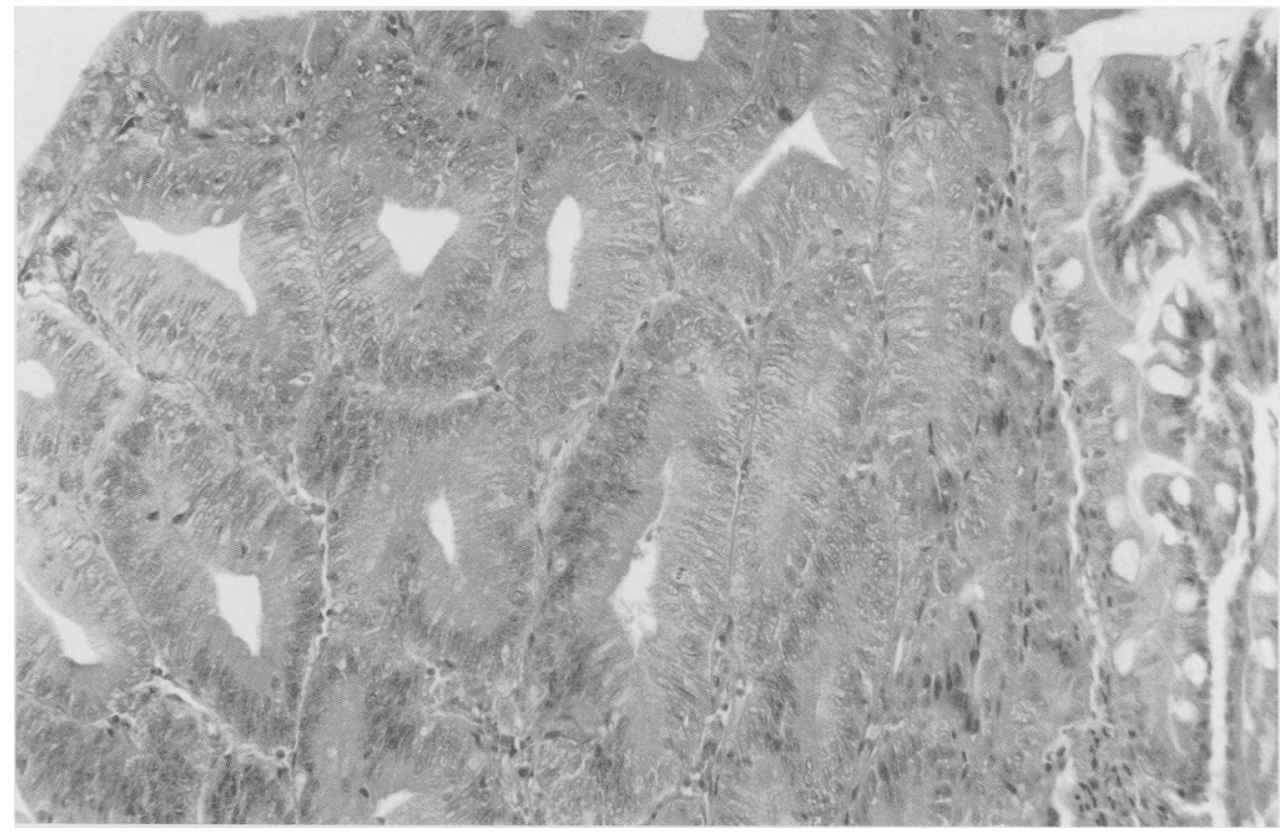

Fig. 9 Duodenal tubular adenoma from a patient with familial adenomatous polyposis. The adenomatous epithelium (left) is contrasted with the more normal duodenal epithelium (right). $(H+E)$. 
reported in Japanese patients where a high incidence of gastric adenoma is known to occur independently of familial adenomatous polyposis. To date no series of endoscopic examinations have been large enough to estimate the true prevalence of gastroduodenal polyps. It is not generally appreciated that gastric polyps in this syndrome are of the fundic gland type but that duodenal polyps seem to be adenomas. The results of this study would bear that out. Upper gastrointestinal adenomas almost certainly predispose to malignancy. Periampullary carcinoma was first described in association with this disorder by Cabot $^{13}$ and the number of reported cases of this otherwise rare tumour in association with familial adenomatous polyposis have increased steadily. ${ }^{121+}$ Indeed today as family awareness and surveillance coupled with prophylactic colectomy is preventing death from colorectal cancer, periampullary adenocarcinoma seems to be the most common malignant epithelial tumour occurring in these patients.

We have studied 100 patients prospectively in order to determine the prevalence and nature of upper gastrointestinal polyps. Overall $46 \%$ of those studied had such polyps with $35 \%$ of patients having adenomas which carry a potential risk for subsequent malignancy. There seems to be a trend favouring the occurrence of adenomas in individuals with stigmata of Gardner's syndrome which is significant. In the literature, however, Bülow" found adenomas in the stomach or duodenum of $50 \%$ of 26 patients he studied who had no stigmata of Gardner's syndrome. Other studies including individuals with extracolonic manifestations report rates in the same range. "We agree that the presence of extracolonic manifestations does not predict the occurrence of gastroduodenal polyps although in our own study duodenal adenomas were more common in Gardner's syndrome. No study to date has looked at the ages of patients exhibiting gastric or duodenal polyps. We have shown that the incidence of adenomas is higher in older patients. It is reasonable to believe that polyps may develop in persons shown initially to be free of them. Thus until longer follow up is available repeated endoscopic surveillance of affected family members should be undertaken.

Bussey $^{15}$ in reviewing the St Mark's Hospital experience estimated an incidence of $4 \%$ for developing periampullary carcinoma in patients surviving five years or more after colectomy. Most of his patients were men and most had evidence of Gardner's syndrome. In reviewing 199 patients with familial adenomatous polyposis managed at the Cleveland Clinic, four cases of periampullary carcinoma have been diagnosed and treated over a period of 30 years. Three were men and one woman and three had stigmata of Gardner's syndrome. The

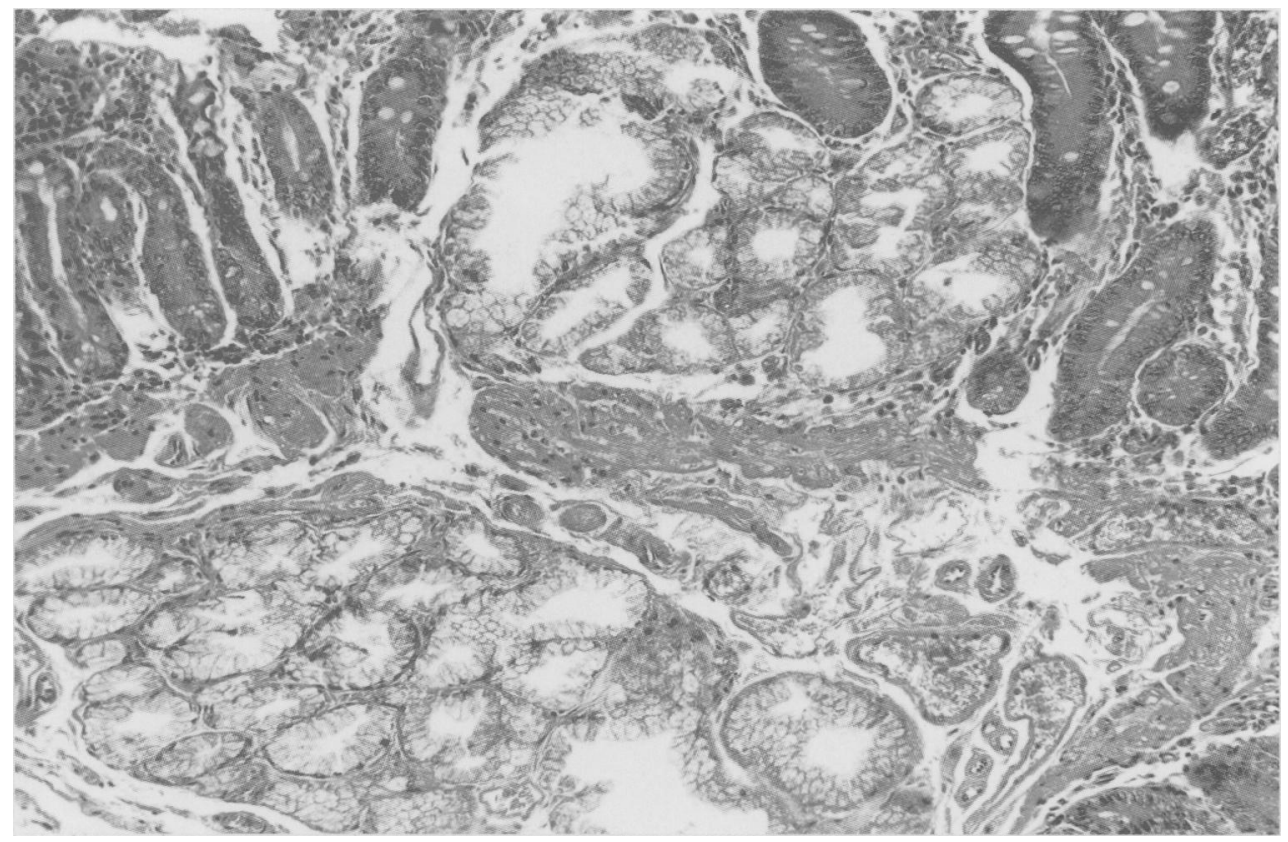

Fig. 10 Section of duodenum containing Brunner's glands from the same patient illustrated in Figure 9. The Brunner's glands appear prominent and are associated with mild cystic dilatation. $(H+E)$. 
ages of these four patients at the time of diagnosis was 28 years, 55 years, 60 years, and 66 years. This represents a prevalence of approximately $2 \%$ in our patients. All patients developing periampullary carcinoma have died of the disease. The evidence that carcinoma arises in duodenal adenomatous polyposis is circumstantial and similar to that implicating adenomas in the aetiology of colorectal cancer. In all four cases treated at our institution there was villous adenoma adjacent to the malignancy. Kozuka et $\mathrm{al}^{16}$ found adenomas in association with duodenal carcinoma in non-polyposis patients. In 18 of 22 cases he studied he observed histological transition from adenoma to carcinoma in several instances. It is reasonable to believe that untreated, these adenomas could progress to invasive malignancy. Gastric fundic gland polyps appear to be common in familial adenomatous polyposis and so far have not been implicated in the cancer sequence. Gastric cancer has been reported in association with familial adenomatous polyposis ${ }^{1718}$ but there does not appear to be an excess of such carcinomas above the number seen in the general population. The majority of gastric cancers reported in association with familial adenomatous polyposis have been in Japanese patients, ${ }^{5}$ a population known to be at higher risk for both gastric adenoma and gastric carcinoma.

At present gastroduodenoscopy of all patients confirmed as having familial adenomatous polyposis is recommended as soon as the diagnosis is made. Any polyps seen should be recorded and representative biopsies taken. Biopsies of the duodenum in the region of the papilla of Vater should also be taken routinely even in the absence of macroscopic lesions as we and others have demonstrated villous changes in flat, apparently normal mucosa at that site..$^{6 \times 1011}$ If adenomas are found these can be most efficiently eradicated by endoscopic destruction. As the adenomas are frequently multiple, they often require multiple treatments. At present we are repeating endoscopy after destructive therapy at six to 12 week intervals until no polyps remain. The examination is then carried out six monthly as long as no new polyps are seen. If the initial examination was normal or if only fundic gland polyps were noted, endoscopy is repeated in three years.

The natural history of upper gastrointestinal polyps in familial adenomatous polyposis not known at this time and our current therapy of adenomas is empiric. Consideration is being given to a prospective randomised study comparing endoscopic destruction with simple surveillance in an effort to better understand the true implications of these lesions in terms of the magnitude of cancer risk. It should be remembered, however, that in our retrospective series of patients treated with colectomy and ileorectal anastomosis (in press) more patients have died of periampullary carcinoma than rectal cancer. It should also be noted that age in itself may not relate to the chance of developing duodenal cancer even though the number of duodenal adenomas increases with age. The four patients developing duodenal cancer in our series range from 28 to 66 years.

It is hoped that with further surveillance and study of these upper gastrointestinal lesions that a better understanding of their natural history will be obtained and hopefully lead to the formulation of a more definitive management plan.

\section{References}

1 Cripps HW. Two cases of disseminated polyps of the rectum. Trans Pathol Soc Lond 1882; 33: 165-8.

2 Gardner EJ, Richards RC. Multiple cutaneous and subcutaneous lesions occurring simultaneously with hereditary polyposis and osteomatosis. Am J Human Genet 1953; 5: 139-47.

3 Sener SF, Miller HH, DcCosse JJ: The spectrum of polyposis. Surg Gynecol Obstet 1984; 159: 525-32.

4 Hoffman DC, Goligher JC. Polyposis of the stomach and small intestine in association with familial polyposis coli. Br J Surg 1971; 58: 126-8.

5 Utsunomiya J, Maki T, Iwama T, et al. Gastric lesions of familial polyposis coli. Cancer 1974; 34: 745-54.

6 Yao $T$, Iida $M$, Ohsato $K$, Watanabe $H$, Omae $T$. Duodenal lesions in familial polyposis of the colon. Gastroenterology 1977; 73: 1086-92.

7 Watanabe H, Enjoji M, Yáo T, Iida M, Ohsato K. Accompanying gastro-enteric lesions in familial adenomatosis coli. Acta Pathol Jpn 1978; 27: 823-39.

8 Ranzi T, Castagnone D, Velio P, Bianchi P, Polli E. Gastric and duodenal polyps in familial polyposis coli. Gut 1981; 22: 363-7.

9 Järvinen H, Nyberg M, Peltokallio P. Upper gastrointestinal tract polyps in familial adenomatosis coli. Gut 1983; 24: 333-9.

10 Burt RW, Berenson MM, Lee RG, Tolman KG, Freston JW, Gardner EJ. Upper gastrointestinal polyps in Gardner's syndrome. Gastroenterology 1984; 86: 295301 .

11 Bülow S, Lauitsen KB, Johansen A, Svendsen LB, Søndergaard JO. Gastroduodenal polyps in familial polyposis coli. Dis Colon Rectum 1985; 28: 90-3.

12 Sugihara K, Muto T, Kamiya J, Konishi F, Sawada T, Morioka Y. Gardner's syndrome associated with periampullary carcinoma, duodenal and gastric adenomatosis. Dis Colon Rectum 1982; 25: 766.

13 Cabot RC. Case records of the Massachusetts General Hospital: Case 21061. N Engl J Med 1935; 212: 263-5.

14 Jones TR, Nance FC. Periampullary malignancy in Gardner's syndrome. Ann Surg 1977; 185: 565-73.

15 Bussey HJR. Familial polyposis coli. Family studies, histopathology, differential diagnosis and results of treatment. Baltimore, Maryland: The Johns Hopkins University Press, 1975. 
16 Kozuka S, Tsubone M, Yamaguchi A, Hachisuka K. Adenomatous residue in cancerous papilla of Vater. $G u t$ 1981; 22: 1031-4.

17 Haglund V, Fork FT, Genell S, Rehnberg O. Villous adenomas in the duodenum. Br J Surg 1985; 72: 26-8

18 Murphy ES, Mireles M, Beltran A. Familial polyposis of the colon and gastric carcinoma. Concurrent condition in a 16-year-old boy. JAMA 1962; 179: 1026-8. 